Leda Leal Ferreira ${ }^{1}$

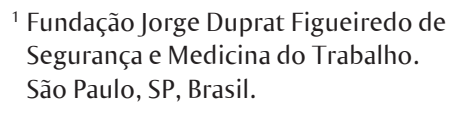

${ }^{1}$ Fundação Jorge Duprat Figueiredo de Segurança e Medicina do Trabalho. São Paulo, SP, Brasil.

Contato:

Leda Leal Ferreira

E-mail:

ledalefe@gmail.com

Médica, doutora em Ergonomia pela Universidade Paris 13. Aposentou-se da Fundacentro - SP onde foi pesquisadora do Setor de Ergonomia por mais de trinta anos.

\section{Sobre a Análise Ergonômica do Trabalho ou AET}

\author{
About Ergonomic Work Analysis or EWA
}

A expressão "análise ergonômica do trabalho" é pouco conhecida entre nós. Foi apenas a partir da década de 1990, do século passado, que começou a ser mais empregada graças, principalmente, à publicação de uma nova versão de uma das normas que disciplinam as matérias de segurança e saúde do trabalhador no Brasil, a qual dizia textualmente: "cabe aos empregadores realizar a análise ergonômica do trabalho". Trata-se da Norma Regulamentadora de Ergonomia 17, ou NR 17, do Ministério do Trabalho e Emprego (BRASIL, 1990) que, em sua nova versão, ampliava o campo normativo da ergonomia. Anteriormente restrito a conselhos sobre como levantar e carregar pesos, ela passou a incluir mais quatro itens: o mobiliário de trabalho, algumas condições dos ambientes de trabalho, os equipamentos (todos os equipamentos) de trabalho e, a maior novidade, a organização do trabalho que, para efeito da norma, incluía o "conteúdo do trabalho", os "modos operatórios", as regras e tempos de trabalho.

O novo conteúdo da NR 17 foi bastante influenciado pelo que, na época, era chamado de ergonomia francofônica e que era, nada mais nada menos, do que a ergonomia que estava sendo desenvolvida no então Laboratório de Ergonomia, do prestigiado Conservatório Nacional de Artes e Ofícios, o CNAM (em francês), de Paris. Por lá, graças à generosa acolhida que recebiam de seu diretor, o saudoso Professor Alain Wisner, passaram dezenas de brasileiros - médicos, psicólogos engenheiros - que, de retorno ao Brasil, tratavam de pôr em prática o que lhes parecia mais significativo, dentre o que tinham aprendido. Foi o que aconteceu quando da discussão da nova versão da norma (BRASIL, 2002), da qual participaram ex-alunos do Laboratório de Ergonomia do CNAM.

Mas, se esta ergonomia tentava responder às demandas sociais que chegavam àquele laboratório, muitas delas vindas do forte movimento sindical francês da época, o mesmo não aconteceu por aqui e muitos dos termos por lá utilizados, relativamente claros e compreensíveis para os franceses, quando transportados para cá causaram e continuam causando dúvidas.

Os acasos da vida fizeram com que eu estivesse no Laboratório (que então se chamava Laboratório de Fisiologia do Trabalho e Ergonomia) na época em que estava sendo formulado e sistematizado o que depois veio a ser chamado de Análise Ergonômica do Trabalho ou AET. Ainda guardo uma apostila de capa amarela (DURAFFOURG et al., 1977) que era utilizada por Jacques Duraffourg quando nos ensinava, a nós alunos do curso de especialização, como ir a campo. Acredito que esta apostila tenha sido o embrião do posterior livro Compreender o trabalho para transformá-lo, a prática da ergonomia (GUÉRIN et al., 2001) também escrito por Duraffourg e 
outros membros, ou ex-membros do CNAM, o qual, na sua tradução para o português, é empregado em muitos cursos de ergonomia em nosso país.

É sobre esse período, que identifico algumas das preocupações dos formuladores da AET nos fins da década de 1970, e sobre as quais pretendo desenvolver este texto, esperando que ele possa ser de alguma utilidade para os leitores brasileiros.

\section{A situação de trabalho não é um laboratório}

A principal característica da nova AET era ser um método de análise do trabalho feita em campo, ou seja, baseada no trabalho realizado pelos trabalhadores nas situações de trabalho.

"A situação de trabalho não é um laboratório", dizia Duraffourg em seu curso. Com isso, estava destacando que a análise ergonômica do trabalho que eles estavam então sistematizando se diferenciava daquela praticada em laboratório, no qual se simulava a situação de trabalho, ou mais geralmente um aspecto dela, onde se podia manipular variáveis e onde os sujeitos eram, em geral, estudantes.

Mas se diferenciava também daquela praticada pelas empresas, a famosa "análise de tarefas" de inspiração taylorista na qual, em última instância, nem era preciso observar os trabalhadores em atividade, uma vez que a sua tarefa poderia ser estabelecida em escritórios de engenharia.

\section{A melhoria das condições de trabalho como preocupação principal}

Outra característica importante da AET era seu objetivo: melhorar as condições de trabalho dos trabalhadores cujas práticas estavam sendo analisadas.

Também nesse caso a AET se diferenciava das análises cujo objetivo era aumentar a produtividade ou a qualidade dos produtos. Este apenas poderia ser um resultado esperado, depois que as condições de trabalho fossem modificadas. Melhorar as condições de trabalho era, portanto, um objetivo que se justificava em si mesmo.

E se diferenciava também das análises do trabalho, cujos objetivos eram mudar os comportamentos dos trabalhadores, preocupação em geral de psicólogos e administradores de empresas.

Para garantir esses objetivos, o primeiro passo de uma Análise Ergonômica era a "análise da demanda" quando era avaliado se a demanda, isto é, a solicitação que chegava ao Laboratório, poderia ou não ser aceita e, se o fosse, quais seriam as condições para tal. A ideia era a de que uma vez que se analisava o trabalho de trabalhadores, eles e, se possível, seus representantes (sindicatos ou associações) estariam a par de tudo o que ia acontecer, além de receberem os resultados finais, precauções para que os objetivos da análise não fossem deturpados ou esquecidos. A situação de trabalho não é uma situação experimental, e tudo o que nela acontece tem repercussões políticas importantes, nos ensinavam. Participei de um estudo feito por solicitação da Federação dos Trabalhadores da Indústria de Vestuário, filiada à então poderosa CGT (Confédération Générale du Travail), cuja fase da análise da demanda demorou muitos meses de negociação entre a Federação e as empresas nas quais o estudo seria feito, para ter garantias de que a equipe de pesquisadores poderia fazer observações do trabalho em campo e que os trabalhadores poderiam ser entrevistados na fábrica, sem serem penalizados, entre outras coisas (BARTOLI et al., 1981).

\section{A observação como técnica principal}

Decidir fazer uma análise do trabalho no momento em que ele estava sendo feito (a chamada análise do trabalho "real") exigia a elaboração e utilização de um conjunto especial de técnicas que pudessem ser usadas sem atrapalhar (muito) a atividade de quem estava trabalhando, nem alterar (muito) a situação que se queria compreender. Escolheu-se a observação do ergonomista como técnica principal. Mas o que deveria ser observado? Logicamente, apenas o que era observável, por exemplo, as posturas corporais ou de segmentos corporais que os trabalhadores adotam em uma determinada situação; as comunicações que trocam entre si; os produtos ou instrumentos que manipulam ou utilizam; o modo como o fazem; os caminhos que percorrem; os percursos que realizam; os documentos que usam; os controles que fazem ou aos quais estão submetidos etc. Essas observações deveriam ser realizadas em diferentes momentos (da jornada, da semana ou até da temporada) para detectar suas variações e se referirem a diferentes trabalhadores. O que iria determinar o quê, quando e como observar era 
uma análise prévia do problema que estava sendo estudado, que começava na análise da demanda, já referida anteriormente, e continuava na análise de uma série de outras informações que deveriam ser levantadas pelo ergonomista na empresa onde o estudo estava sendo feito, e que tratavam tanto de características da população dos trabalhadores, como do posto de trabalho, da empresa e até da atividade econômica em questão. Ou seja, a observação não se justificava por si, mas deveria ser feita em função de uma problemática que se queria conhecer ou de uma hipótese que se queria testar. Além disso, para explicar alguns fenômenos observados, os ergonomistas precisavam conversar com os trabalhadores e, portanto, nenhuma análise era feita apenas de observações, por mais que estas constituíssem sua base: "nenhum instrumento de observação pode substituir o conhecimento dos trabalhadores sobre as tarefas que realizam", ensinavam nossos professores.

\section{A atividade como conceito central}

Escolher analisar o trabalho "real", isto é, tal qual ele estava acontecendo no momento da análise logo se mostrou ser algo bastante complexo, prática e teoricamente. A utilização do conceito de atividade para se referir a esse trabalho não tornou as coisas mais simples. De fato, "atividade" é um conceito tão problemático como "trabalho" e os ergonomistas de então já tinham problemas práticos suficientes para se dedicarem ao desenvolvimento teórico do conceito. De modo que tal atividade começou a ser entendida de maneiras bastante diferentes até pelos próprios ergonomistas. E esse problema persiste até hoje: vai desde sua assimilação como "tarefa" (já ouvi engenheiros falarem que não há diferenças entre esses termos), até desenvolvimentos mais sofisticados, onde a atividade é assimilada ao fazer e à ação.

De qualquer forma, a escolha da atividade serviu para diferenciar esta abordagem de análise do trabalho daquela mais tradicional empregada pelas empresas, baseada na tarefa taylorista. E permitiu também que se formulasse uma ideia que passou a ser uma espécie de marca registrada do grupo: a ideia da diferença entre o trabalho real (ou a atividade, o trabalho vivo) e o trabalho prescrito (ou a tarefa, o trabalho morto).

\section{O físico e o mental atuando conjunta e harmonicamente}

"Se uma atividade tiver um componente físico predominante, procure seu componente mental. Por outro lado, se tiver um componente mental predominante, procure seu componente físico. E tente integrar os dois”. Este simples conselho, também dado por Duraffourg em nosso curso, se mostrou extremamente heurístico e ajudou a ampliar a compreensão do que estávamos analisando.

Era uma tentativa de entender o homem na sua globalidade e integralidade, se diferenciando assim das abordagens, predominantes nas análises do trabalho até hoje, que se ocupavam apenas de um aspecto das atividades dos trabalhadores ou das que, mesmo considerando vários aspectos, não os relacionava entre si, se contentando em listá-los.

Passados quarenta anos dessa época, me parece que estas cinco características da AET permanecem válidas, tanto que se pode definir a AET como um método de análise do trabalho baseado na observação da atividade tal qual está acontecendo no momento da análise e cujo objetivo maior é melhorar a situação de trabalho.

No entanto, me parece que ainda falta muito para essa análise mostrar todas as suas potencialidades. Entre outros, cito alguns desafios atuais:

1-Aprofundar os aspectos teóricos do conceito de atividade: como já mencionado, uma das grandes dificuldades teóricas da ergonomia repousa no conceito de atividade, que é usado em diferentes acepções, quase nunca explicitadas. Assim, atividade pode ser usada no sentido de atividade física (me parece que este é um dos usos mais frequentes do termo), mas também pode ser utilizada num sentido mais amplo, como a parte subjetiva do processo de trabalho (considerando a contribuição do sujeito nesse processo). Talvez não caiba aos ergonomistas o trabalho teórico de pesquisa e esclarecimento, dada a sua vocação (e formação) mais prática. Nesse caso, deveriam pedir ajuda a outros tipos de profissionais (penso especialmente na contribuição de filósofos ou linguistas). Atividade é um conceito tão complexo como trabalho e não se pode escapar de tentar explicitá-lo, para a clareza geral.

2-Aprofundar a compreensão das relações entre físico, cognitivo e emocional. Há quarenta anos, quando uma das preocupações dos ergonomistas era avaliar a "carga de trabalho" (conceito que está fora de uso atualmente), se falava em carga física e mental de trabalho. Aos poucos, essa carga mental foi se diferenciando 
em cognitiva e psíquica, ou emocional ou afetiva. Em ambos os casos, houve desenvolvimentos notáveis, fornecidos principalmente pelo desenvolvimento das neurociências, particularmente no caso francês, pela abordagem de Christophe Dejours, o criador da Psicodinâmica do Trabalho e responsável por realçar os aspectos psicológicos e afetivos do trabalho, através da análise do sofrimento e prazer no trabalho. Infelizmente, a formação de ergonomistas não tem conseguido acompanhar essa evolução o que, em parte, é responsável pelo fato de que, na prática, a maioria dos ergonomistas continue a não integrar os aspectos físicos, cognitivos e psicológicos nas suas análises.

3-Aprofundar a compreensão dos aspectos coletivos e sociais do trabalho. A AET tal qual foi formulada há mais de quarenta anos, era antes de tudo uma ergonomia de postos de trabalho individuais e as suas técnicas estavam voltadas para avalições individuais. Os aspectos coletivos do trabalho, embora vislumbrados, eram dificilmente analisados, até porque faltavam ferramentas para isso. O problema era de tal ordem que Wisner sentiu a necessidade de desenvolver outra abordagem - a sua Antropotecnologia - para ampliar o campo de análise das situações de trabalho, aí introduzindo aspectos sociais, culturais e políticos. Embora a preocupação com os coletivos tenha avançado, continua um desafio para os ergonomistas introduzir a dimensão coletiva do trabalho em suas análises.

4-Introduzir história nas análises. As situações de trabalho não são campos de experimentação e, portanto, o modo de abordá-las não é o das ciências experimentais, baseado na detecção e isolamento de variáveis a serem manipuladas. As situações de trabalho estão imersas na história e não considerá-la restringe e até invalida a compreensão das mesmas. São histórias individuais que se entrelaçam com histórias de classes sociais, de ofícios, de profissões, de regiões, de países e de épocas, elementos que são indispensáveis para a compreensão das situações de trabalho presentes.

5-Aprofundar o entendimento da análise da demanda e procurar associar a toda demanda um trabalho de, pelo menos, aproximação com os representantes dos trabalhadores cujo trabalho será analisado. Como já mencionei, a análise da demanda é o primeiro passo de uma AET (na verdade, de qualquer análise do trabalho) e talvez um dos mais importantes porque é nessa fase que se estabelecerá o que será feito a seguir e em que condições. Tenho reparado que esta fase é pouco compreendida e bastante menosprezada em várias análises. Para alguns, a análise da demanda se confunde com análise do problema, o que não é a mesma coisa: toda demanda traz um problema, mas nem todos os problemas têm uma demanda. A situação é mais complicada quando é o próprio ergonomista (em formação ou empregado em uma empresa) que escolhe o problema que quer tratar e começa a fazê-lo sem nenhuma preocupação em explicar para os trabalhadores cujo trabalho será analisado (e muito menos para seus representantes legais) o que pretende fazer e o objetivo de suas análises. Com isso, além de adotar um comportamento eticamente censurável (porque está tratando os trabalhadores como objetos e porque não está explicitando que a finalidade do estudo seja a mudança na situação de trabalho para melhorar suas condições), também coloca em risco a utilidade social de suas análises, desvalorizando seu próprio trabalho como ergonomista.

\section{Referências}

BARTOLI, M. et al. Une approche pluridisciplinaire de l'évolution du travail ouvrier dans une branche industrielle. Le Travail Humain, Paris, v. 44, n. 1, p. 109-168, 1981.

BRASIL. Ministério do Trabalho e Emprego. Manual de aplicação da Norma Regulamentadora $n^{\circ}$ 17. 2. ed. Brasília: MTE, 2002.

. Ministério do Trabalho e Previdência Social. Portaria MTPS no 3.751, de 23 de novembro de 1990. NR-17 Ergonomia. Diário Oficial [da] República Federativa do Brasil, Brasília, DF, 26 nov. 1990. Disponível em: <http:// portal.mte.gov.br/data/files/FF8080812BE914E6012BEFBAD7064803/nr_17.pdf>. Acesso em: 11 maio 2015.

DURAFFOURG, J. et al. Analyse des activités de l'homme en situation de travail, principes de methodologie ergonomique. Paris: Laboratoire de Physiologie du Travail et d'Ergonomie, 1977.

GUÉRIN, F. et al. Compreender o trabalho para transformá-lo: a prática da ergonomia. São Paulo: Blucher, 2001. 